\title{
Erratum to: A Comparative Study on the In Vitro Effects of the DNA Methyltransferase Inhibitor 5-Azacytidine (5-AzaC) in Breast/Mammary Cancer of Different Mammalian Species
}

\author{
Rebecca M. Harman ${ }^{1}$ - Theresa M. Curtis ${ }^{2}$ • David J. Argyle ${ }^{3} \cdot$ Scott A. Coonrod $^{1}$.
}

Gerlinde R. Van de Walle ${ }^{1}$

Published online: 26 April 2016

(C) Springer Science+Business Media New York 2016

Erratum to: J Mammary Gland Biol Neoplasia

DOI 10.1007/s10911-016-9350-y

Figure $2 \mathrm{~A}$ in the original version of this article contained an incorrect image. The correct Figure 2 is shown below. This error does not have any influence on the data discussed and conclusions drawn in the article.

The online version of the original article can be found at //http:dx.doi.org/ 10.1007/s10911-016-9350-y.

Gerlinde R. Van de Walle grv23@cornell.edu

1 Baker Institute for Animal Health, College of Veterinary Medicine, Cornell University, Ithaca, NY 14850, USA

2 Department of Biological Sciences, State University of New York at Cortland, Cortland, NY, USA

3 Royal (Dick) School of Veterinary Studies and Roslin Institute, The University of Edinburgh, Edinburgh, UK 
A

canine tissue

(grade 1/2 complex

mammary carcinoma)

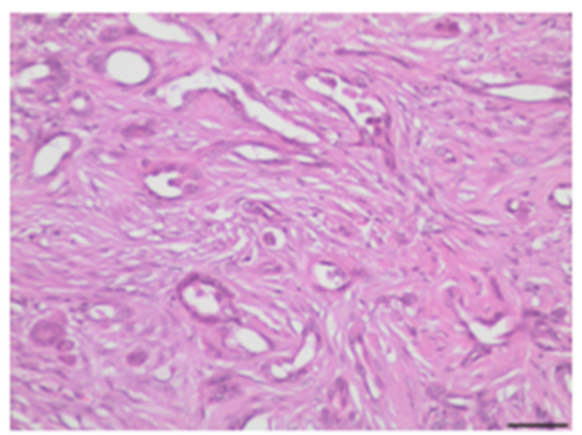

feline tissue

(grade 2 simple

mammary carcinoma)

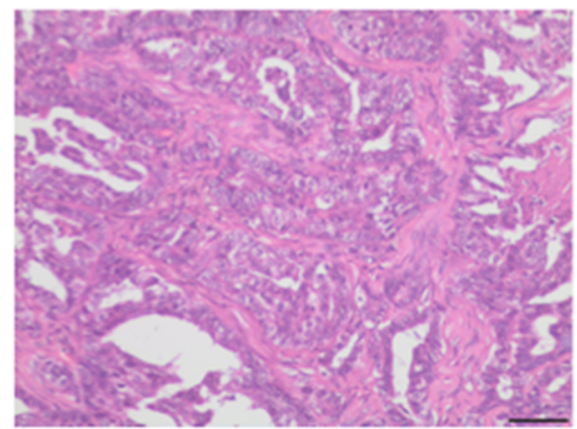

B
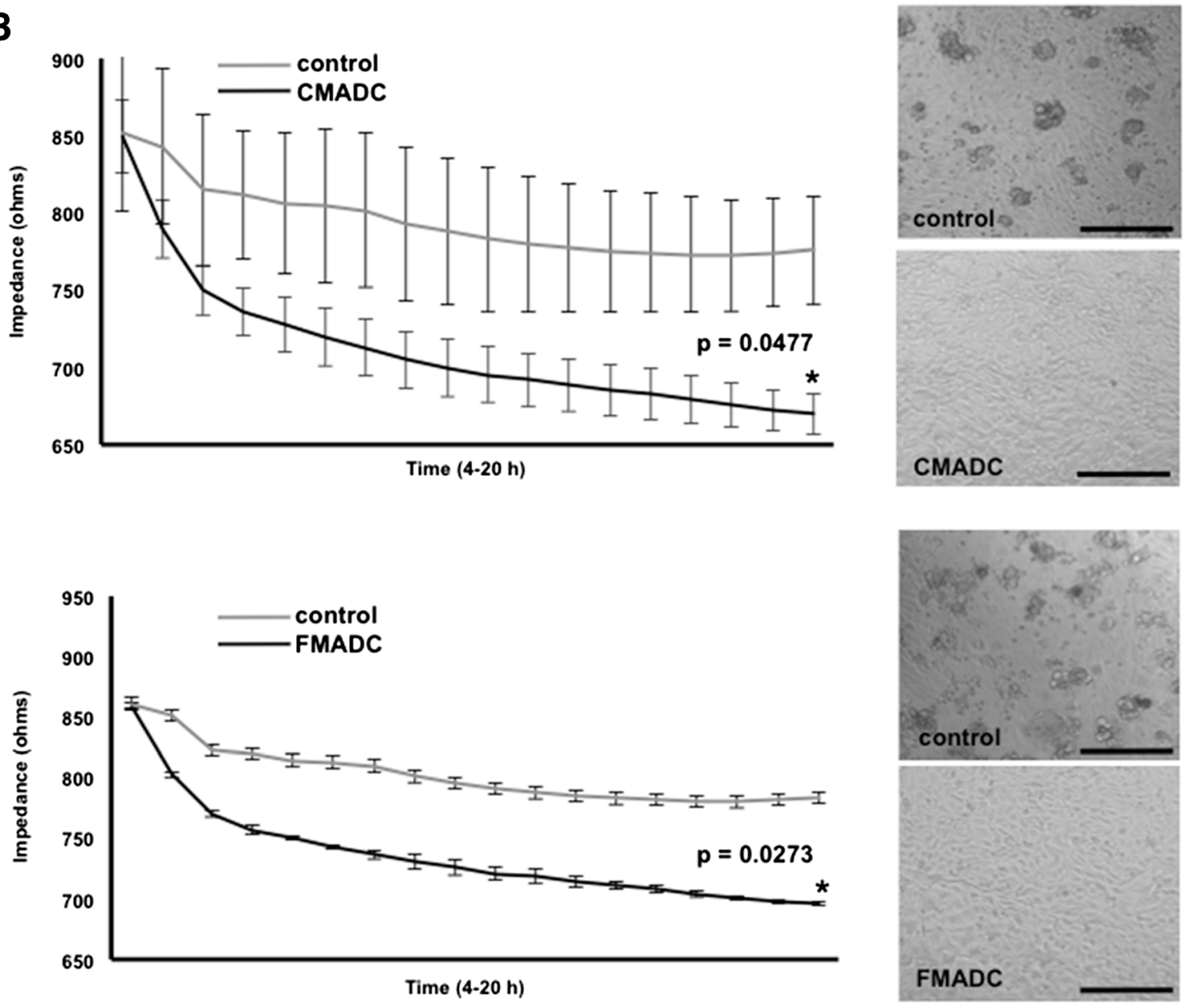